\title{
Coupled Stress-Strain and Electrical Resistivity Measurements on Copper Based Shape Memory Single Crystals
}

\author{
Cezar Henrique Gonzalez $z^{\mathrm{a}}$, Ney Freitas de Quadros ${ }^{\mathrm{a}}$, \\ Carlos José de Araújo ${ }^{\mathrm{b}}$, Michel Morin ${ }^{\mathrm{c}}$, Gerard Guénin ${ }^{\mathrm{c}}$ \\ ${ }^{a}$ Universidade Federal de Pernambuco (UFPE), Departamento de Engenharia Mecânica \\ Av. Acadêmico Hélio Ramos, s/n, CDU, 50740-530 Recife - PE, Brazil \\ ${ }^{\mathrm{b}}$ Universidade Federal de Campina Grande, Departamento de Engenharia Mecânica \\ Av. Aprígio Veloso, 882, C.P. 10069, 58109-970 Campina Grande - PB, Brazil \\ 'Institut National des Sciences Appliquées de Lyon (INSA), Groupe d'Études de Métallurgie \\ Physique et Physique des Matériaux, Bâtiment Blaise Pascal \\ 7 Avenue Jean Capelle, 69621 - Villeurbanne - France
}

Received: January, 30, 2003; Revised: October, 13, 2003

\begin{abstract}
Recently, electrical resistivity (ER) measurements have been done during some thermomechanical tests in copper based shape memory alloys (SMA's). In this work, single crystals of Cu-based SMA's have been studied at different temperatures to analyse the relationship between stress $(\sigma)$ and ER changes as a function of the strain $(\varepsilon)$. A good consistency between ER change values is observed in different experiments: thermal martensitic transformation, stress induced martensitic transformation and stress induced reorientation of martensite variants. During stress induced martensitic transformation (superelastic behaviour) and stress induced reorientation of martensite variants, a linear relationship is obtained between ER and strain as well as the absence of hys teresis. In conclusion, the present results show a direct evidence of martensite electrical resistivity anisotropy.
\end{abstract}

Keywords: shape memory effects, martensitic transformation, electrical resistivity, superelasticity

\section{Introduction}

Shape memory alloys (SMA's) present different phenomena (one way shape memory effect, two way shape memory effect, superelasticity and rubber-like behaviour) which can be induced by changes in temperature and/or mechanical stress. All those effects are characterised by modifications in crystalline structure of the SMA. The electrical resistivity (ER) is one, among many others experimental techniques used to study these metallic alloys. Its main application is for determination of transformation temperatures, due to the susceptibility of ER to detect modifications in the crystalline structure of the SMA undergoing phase transformation during heating and cooling ${ }^{1,2}$. ER is also used to measure the evolution of shape memory effect during ageing in parent phase and low temperature phase (martensitic stabilisation) $^{3-6}$.

*e-mail: gonzalez@ufpe.br

Articles presented at the XV CBECIMAT, Natal - RN, November de 2002.
More recently, ER measurement has been used to follow the thermomechanical shape memory behaviour under applied load ${ }^{7}$. The ER is affected in this case by the strain, structural modifications, reorientation of martensite variants and also by the introduction and rearrangement of defects ${ }^{8-10}$. The knowledge of ER behaviour during these events has special importance for technological applications. Indeed, it can be used to drive the material performance from electronic control.

Electrical resistivity measurements coupled with thermomechanical tests in Ti-Ni polycrystalline alloys have confirmed a linear variation of ER as a function of $\operatorname{strain}^{11,12}$. The ER was also used to study the Two Way Shape Memory Effect (TWSME) phenomenon as a function of stress, strain and number of cycles during training process ${ }^{9,12-14}$. 
Depending of the thermomechanical process, a polyvariant or a single variant martensite can be induced from a $\beta$-phase single crystal of copper based SMA. A cooling from the parent phase without applied stress produces a martensite phase with different orientation of variants (polyvariant 24 possible orientation of variants). The self-accommodation process of martensite into SMA explains because the shape of the sample does not change significantly. It is also possible to obtain a single variant by stress induced martensitic transformation. From a single crystal of parent phase, each possible orientation of martensite corresponds to a different shear direction. For a fixed tensile axis, it is then possible to calculate a Schmidt factor for each one of the 24 possible variants. During superelastic tests at temperatures higher than the austenite finish temperature $\left(\mathrm{T}>\mathrm{A}_{\mathrm{F}}\right.$ ), the stress induced variant is the one which leads to the highest $S c h m i d t$ factor. The theoretical maximum recoverable strain by superelasticity is calculated to be around $8.6 \%$ for $\mathrm{Cu}-\mathrm{Al}-\mathrm{Ni}$ SMA's with a Schmidt factor close to $0.5^{15}$. Figure 1 shows the obtained superelastic strain versus the crystallographic direction of the tensile axis (in parent cubic phase coordinates).

In this work, electrical resistivity coupled with stressstrain measurements on single crystals of $\mathrm{Cu}-\mathrm{Zn}-\mathrm{Al}$ and

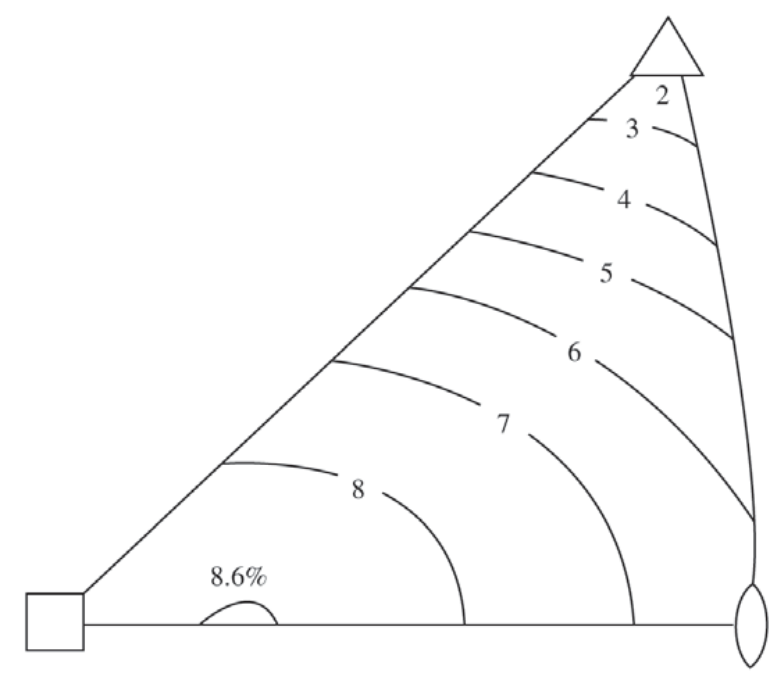

Figure 1. Stereographic triangle for calculation of transformation strain in $\mathrm{Cu}-\mathrm{Al}-\mathrm{Ni}$ alloys ${ }^{15}$.
$\mathrm{Cu}-\mathrm{Al}$-Be SMA's were performed using a special tensile machine. These measurements were carried out at different temperatures and for different crystallographic orientations of the samples in relation to the tensile axis.

\section{Experimental Procedure}

The $\mathrm{Cu}-\mathrm{Zn}-\mathrm{Al}$ and $\mathrm{Cu}-\mathrm{Al}-\mathrm{Be}$ alloys for this study were elaborated in an induction-melting furnace. Single crystals were prepared by a modified Bridgman method ${ }^{16}$. The Table 1 show the nominal chemical compositions of the studied alloys with the respective phase transformation temperatures obtained by Differential Scanning Calorimetry (DSC, Mettler TA 3000) and electrical resistivity measurements.

Tensile samples with the following dimensions were prepared by electro-erosion: gage/gauge (useful) length $=10 \mathrm{~mm}$, width $=4 \mathrm{~mm}$ and thickness $=1.2 \mathrm{~mm}$. The superficial deformed layer was eliminated by chemical etching in an aqueous solution of $15 \% \mathrm{HNO}_{3}$. Then the Samples were annealed at $850^{\circ} \mathrm{C}$ for $10 \mathrm{~min}$ and quenched into water at room temperature. After, its were aged at $100{ }^{\circ} \mathrm{C}$ during $1 \mathrm{~h}$ in order to eliminate excess of vacancies and to stabilise the order of the $\beta$ phase.

The samples were tested in a specific tensile machine specially designed to thermomechanical tests in SMA's ${ }^{17}$. This machine, described in Fig. 2, has a pneumatic motor system that applies the mechanical loading directly on the sample without any dry friction. The temperature of the sample is maintained constant and homogeneous by keeping it into a silicone oil bath with forced circulation. This system also allows perform thermal cycles between - 30 and $150^{\circ} \mathrm{C}$. Tensile tests were carried out with a strain rate of $0.2 \% / \mathrm{min}$. After each test, the samples were heated up to $100{ }^{\circ} \mathrm{C}$ for elimination of possible residual martensite.

ER measurements are carried out by a conventional four terminal DC method. For these measurements a constant electrical current $(i)$ pass through the sample and two conduct wires are spot-welded on the sample close to the isolated ceramic grips of the extensometer for the measurement of the voltage signal $(\Delta \mathrm{V})$, as shown in Fig. 3. As electrical current is always constant, the ER change in percentage corresponds to the percentile change in $\Delta \mathrm{V}$.

The ER variations are calculated by Eq. 1, derived from Ohm's law considering that thermoelastic martensitic transformation induces a negligible volume change ${ }^{9,11}$.

Table 1. Nominal chemical compositions and phase transformation temperatures of the studied alloys.

\begin{tabular}{lcccccccc}
\hline Sample & $\mathrm{Cu}(\mathrm{wt} . \%)$ & $\mathrm{Al}(\mathrm{wt} . \%)$ & $\mathrm{Zn}(\mathrm{wt} . \%)$ & $\mathrm{Be}(\mathrm{wt} . \%)$ & $\mathrm{A}_{\mathrm{S}}\left({ }^{\circ} \mathrm{C}\right)$ & $\mathrm{A}_{\mathrm{F}}\left({ }^{\circ} \mathrm{C}\right)$ & $\mathrm{M}_{\mathrm{S}}\left({ }^{\circ} \mathrm{C}\right)$ & $\mathrm{M}_{\mathrm{F}}\left({ }^{\circ} \mathrm{C}\right)$ \\
\hline CZA & 76.60 & 15.40 & 8.00 & - & 40 & 42 & 38 & 32 \\
CAB-1 & 87.58 & 12.00 & - & 0.42 & 2 & 18 & 9 & -11 \\
CAB-2 & 87.52 & 12.00 & - & 0.48 & -1 & 16 & 2 & -13 \\
\hline
\end{tabular}




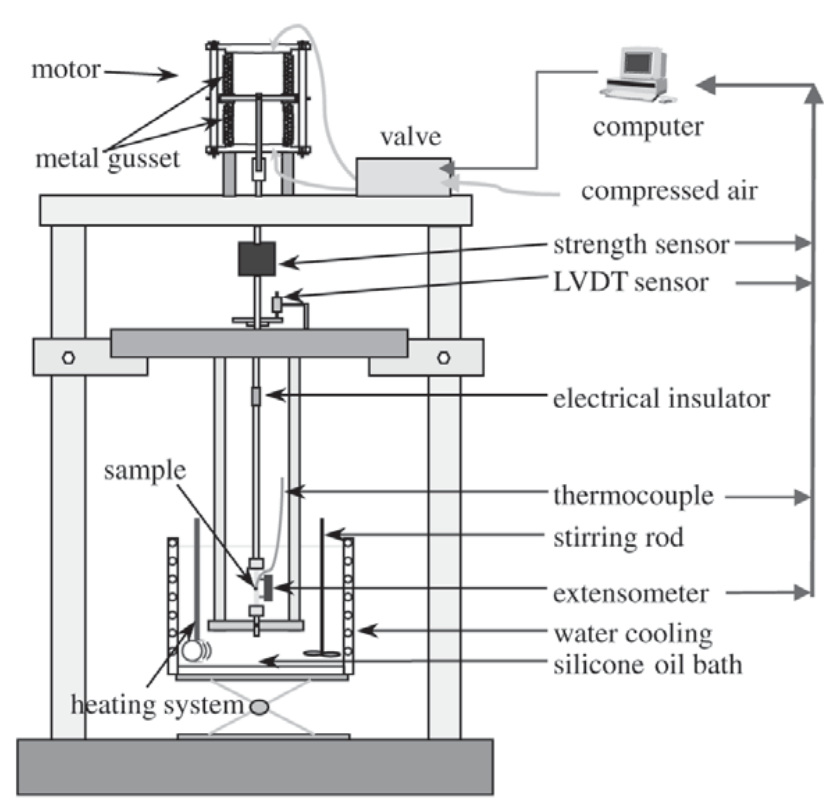

Figure 2. Schematic representation of the pneumatic tensile machine.

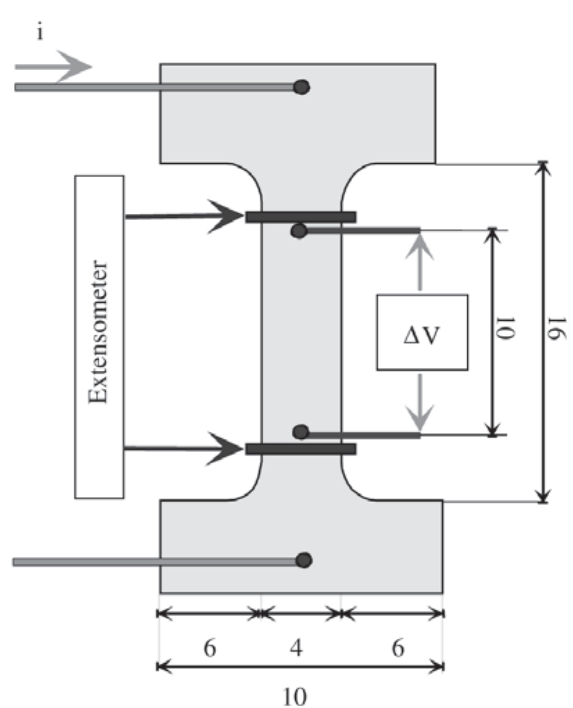

Figure 3. Schematic representation of tensile sample with extensometer and electrical resistance measurement (dimensions in $\mathrm{mm}$ ).

$$
\frac{\Delta \rho_{\varepsilon}}{\rho_{\varepsilon_{\mathrm{o}}}}=\frac{\Delta \mathrm{R}_{\varepsilon}}{\mathrm{R}_{\varepsilon_{\mathrm{o}}}}-2 . \varepsilon
$$

where $R_{\varepsilon}$ and $\rho_{\varepsilon}$ are respectively the electrical resistance and electrical resistivity for a given strain $\varepsilon, R_{\varepsilon_{0}}$ and $\rho_{\varepsilon 0}$ corresponding to the properties in the initial state just before the test. Equation 1 is applied to obtain the true electrical resis- tivity change by removing the contribution of geometrical alterations of the sample.

Some tensile samples were selected for in situ observations of microstructural changes due to application of mechanical loading. For this one, it was employed an optical microscope with an attachment apparatus for application of tensile load.

\section{Results and Discussions}

Figures 4 and 5 show the results obtained for $\mathrm{Cu}-\mathrm{Zn}-\mathrm{Al}$ and $\mathrm{Cu}-\mathrm{Al}-\mathrm{Be}$ alloys (samples $\mathrm{CZA}$ and $\mathrm{CAB}-1$ ), respectively.

\subsection{Thermal transformation}

Figures $4 \mathrm{a}$ and $5 \mathrm{a}$ show the resistivity change versus temperature at zero stress, with indication of the phase transformation temperatures. The arrows indicate the temperatures chosen for tensile tests in each one alloy sample. Comparison of these two figures shows that the resistivity in the martensitic phase is higher than the one of austenitic phase. After martensitic transformation by cooling, resistivity is increased of about $22 \%$ for $\mathrm{Cu}-\mathrm{Zn}-\mathrm{Al}$ and $17 \%$ in the case of $\mathrm{Cu}-\mathrm{Al}-\mathrm{Be}$. This resistivity change corresponds to the formation of randomly oriented thermal martensite variants (self-accommodation phenomenon). It can also be noted that the hysteresis of $\mathrm{Cu}-\mathrm{Zn}$ - $\mathrm{Al}$ is smaller $\left(\approx 6^{\circ} \mathrm{C}\right)$ than the one of $\mathrm{Cu}$-Al-Be alloy $\left(\approx 12^{\circ} \mathrm{C}\right)$, both taken at the midway of cooling and heating curves.

\subsection{Test in the martensitic phase}

Figures $4 \mathrm{~b}$ and $5 \mathrm{~b}$ show the results obtained during tensile test in the martensite phase (at $\mathrm{T}<\mathrm{M}_{\mathrm{F}}$ ) for both samples. In this case, the initial state of the sample is polyvariant martensite ${ }^{18}$. During the tensile test, the variant that has the highest Schmidt factor increases in the expense of the other variants $^{19}$. Therefore, resistivity change is only due to the reorientation of martensite variants. The maximum values obtained for $\frac{\Delta \rho_{\varepsilon}}{\rho_{\varepsilon_{\mathrm{o}}}}$ are of the order of $15 \%$ for $\mathrm{Cu}-\mathrm{Zn}-\mathrm{Al}$ and $12 \%$ for $\mathrm{Cu}-\mathrm{Al}-\mathrm{Be}$ alloy. The characteristic slopes of ER versus strain curves are indicated in the Figs. $4 \mathrm{~b}$ and $5 \mathrm{~b}$,

denoted by $\mathrm{p}\left(\mathrm{p}=\frac{\mathrm{d}\left(\Delta \rho \varepsilon / \rho \varepsilon_{0}\right)}{\mathrm{d} \varepsilon}\right)$.

\subsection{Test in the austenitic phase}

Figures $4 \mathrm{c}$ and $5 \mathrm{c}$ show stress-strain and electrical resistivity changes measured at $\mathrm{T}>\mathrm{A}_{\mathrm{F}}$. In this region, the superelastic effect occurs due to appearance of martensite variants as a result of the applied stress ${ }^{20}$. Similarly to the case of thermal martensite, the hysteresis of stress induced martensite transformation is higher for the $\mathrm{Cu}-\mathrm{Al}-\mathrm{Be}$ in comparison with the $\mathrm{Cu}-\mathrm{Zn}-\mathrm{Al}$ alloy. In the case of the tests 

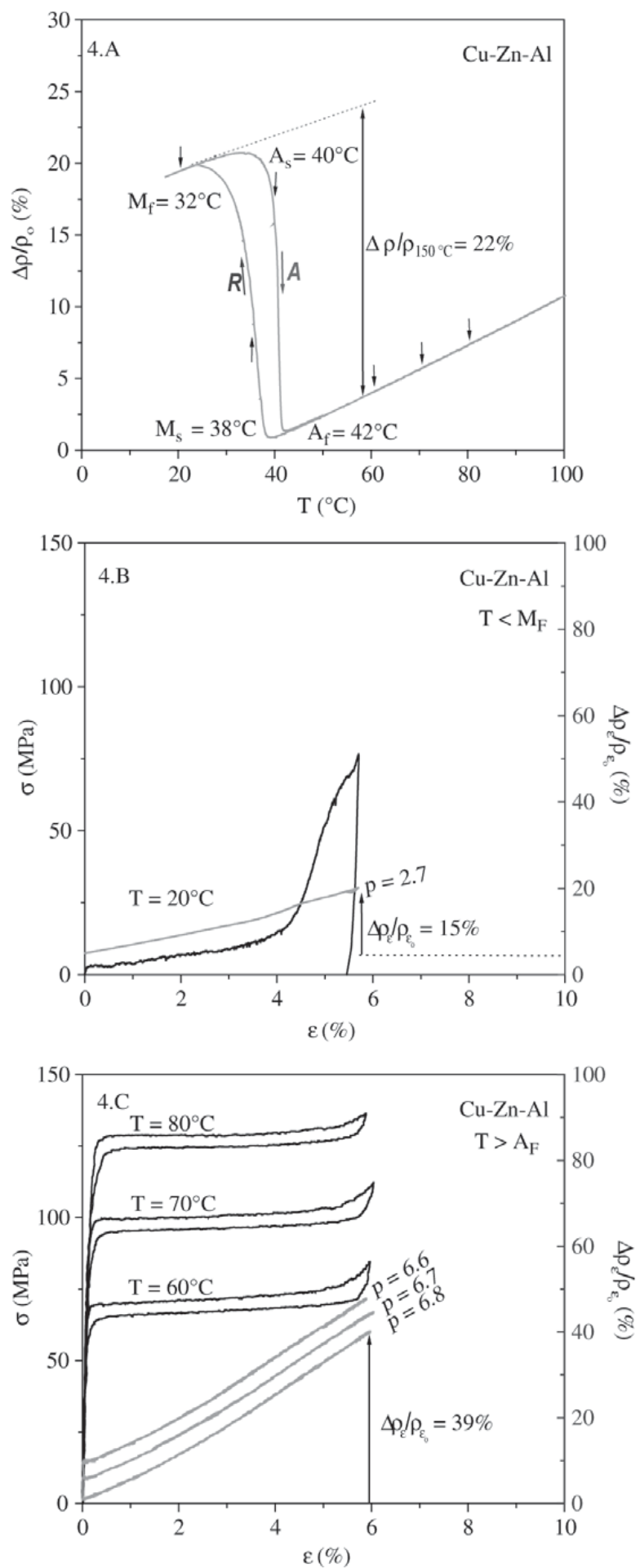

Figure 4. Curves for the $\mathrm{Cu}-\mathrm{Zn}-\mathrm{Al}$ (CZA sample): a) Changes of ER for thermal induced martensitic transformation $(\sigma=0)$; b) Coupled test in the martensitic phase; c) Coupled test in the austenitic phase.
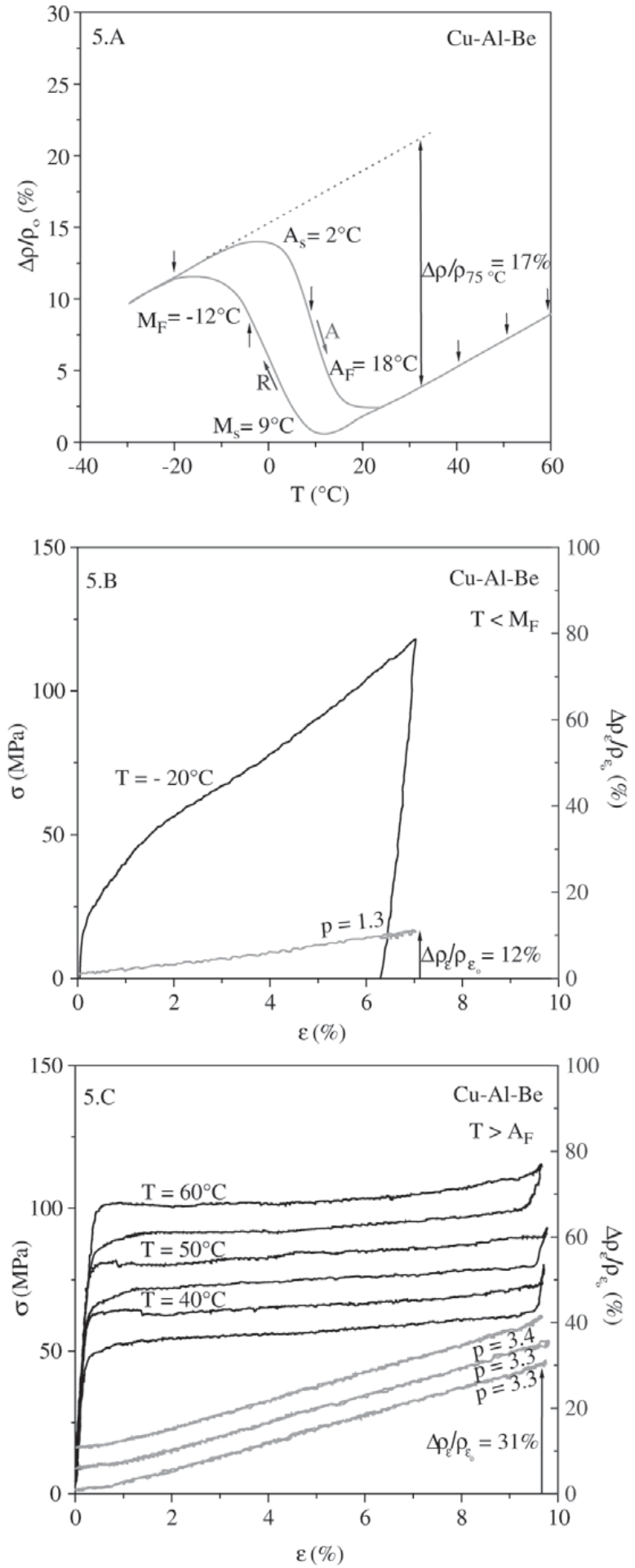

Figure 5. Curves for the $\mathrm{Cu}-\mathrm{Al}-\mathrm{Be}(\mathrm{CAB}-1$ sample): a) Changes of ER for thermal induced martensitic transformation $(\sigma=0)$; b) Coupled test in the martensitic phase; c) Coupled test in the austenitic phase. 
described by Figs. $4 \mathrm{c}$ and $5 \mathrm{c}$, the obtained recoverable maximum strain $\left(\varepsilon_{\max }\right)$ is of the order of $5.9 \%$ for $\mathrm{Cu}-\mathrm{Zn}-\mathrm{Al}$ and 9.6\% for $\mathrm{Cu}-\mathrm{Al}-\mathrm{Be}$ alloy. The observed resistivity change corresponds to the formation of single variants of martensite. These resistivity change values are higher than the ones corresponding to the formation of polyvariant thermal martensite (Figs. 3a and 4a). The obtained values of $\frac{\Delta \rho_{\varepsilon}}{\rho_{\varepsilon_{o}}}$ are of the order of $39 \%$ for $\mathrm{Cu}-\mathrm{Zn}-\mathrm{Al}$ and $31 \%$ for $\mathrm{Cu}-\mathrm{Al}-$ $\mathrm{Be}$ alloy. Theses values, as well as the slopes of the ER curves, do not change with the temperature for $T>A_{F}$. The ER curves are deliberately shifted along the y-axis for presentation because they are almost superposed. It can also be verified that the hysteresis of ER curves is negligible. Therefore, for a same alloy, $\frac{\Delta \rho_{\varepsilon}}{\rho_{\varepsilon_{o}}}$ depends only of superelastic strain. This can be explained by the fact that strain and electrical resistivity changes are directly proportional to the amount of stress induced martensite.

Experimental results obtained from Figs. 4 and 5 are summarised in Table 2. The operation $A$ corresponds to for- mation of a polyvariant martensite by simple thermal cycle. When this self-accommodating structure is stressed, the reorientation process is started, and only one variant becomes dominant in the structure (operation $B$ ). The result of these operations $(A+B=D)$ is a stress oriented single crystal martensite. In the line $D$ of Table 2 , the addition of electrical resistivity change corresponding to the two operations, $A$ and $B$, is reported. The value of this sum is close to the variation of resistivity corresponding to operation $C$, where a single variant of martensite is directly stress induced from a single crystal of austenite. Therefore, a martensite single crystal has been obtained by two different ways, as schematised in Fig. 6.

These measurements show by two ways that the resistivity of a single variant obtained in a particular direction can be larger than the resistivity of the martensite phase with randomly oriented variants ${ }^{16}$. Therefore, it is clear that the martensite single crystal has a large resistivity anisotropy.

\subsection{Superelasticity tests for different orientations of the tensile axis}

Figure 7 shows the results for three superelasticity tests

Table 2. Resistivity changes for each process with the studied samples.

\begin{tabular}{|c|c|c|c|}
\hline Operation & Process & $\begin{array}{r}\text { Resistivity v } \\
\mathrm{Cu}-\mathrm{Zn}-\mathrm{Al}\end{array}$ & $\begin{array}{l}\Delta \rho_{\varepsilon} / \rho_{\varepsilon}(\%) \\
\mathrm{Cu}-\mathrm{Al}-\mathrm{Be}\end{array}$ \\
\hline A & Thermal martensite & 22 & 17 \\
\hline B & Reorientation of variants $\left(\mathrm{T}<\mathrm{M}_{\mathrm{F}}\right)$ & 15 & 12 \\
\hline $\mathrm{C}$ & Induced single variant $\left(T>A_{F}\right)$ & 39 & 31 \\
\hline $\mathrm{D}$ & $A+B \approx C$ & 37 & 29 \\
\hline
\end{tabular}

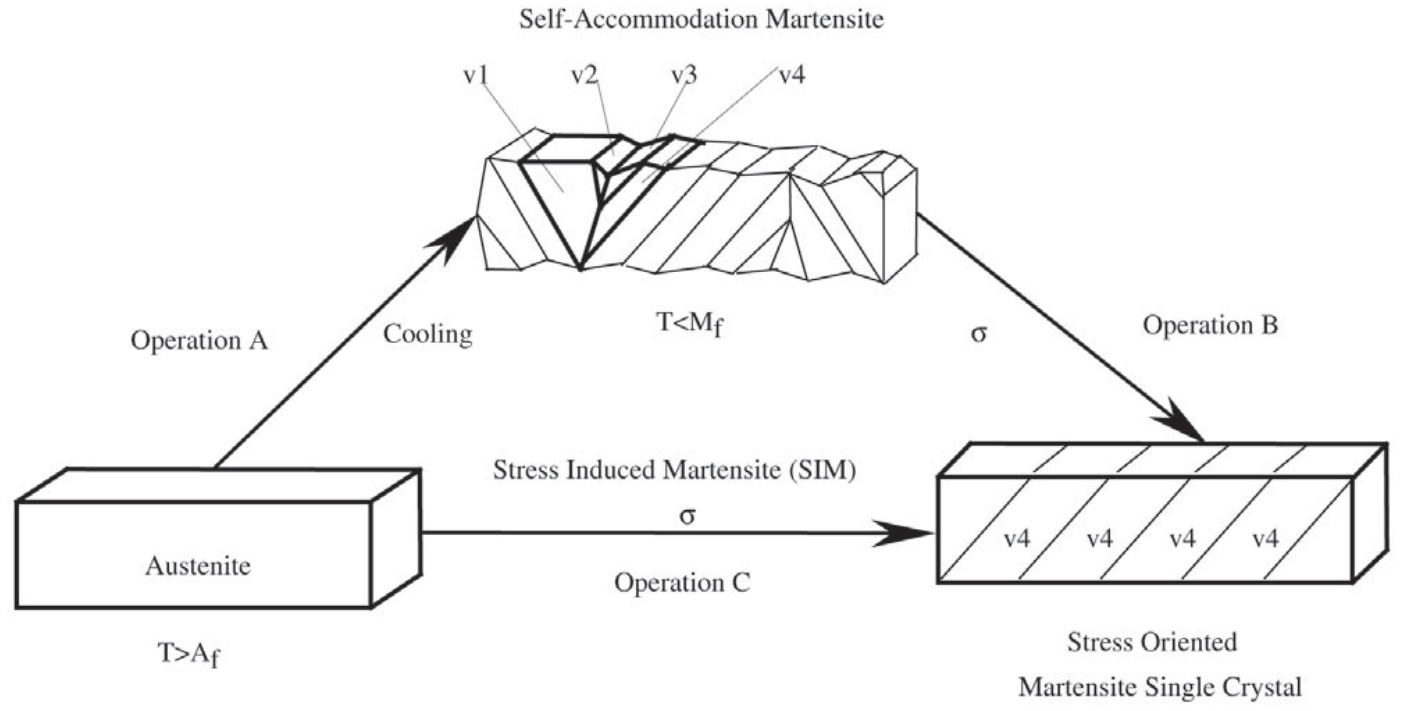

Figure 6. Schema of the two possible ways to obtain martensite single crystal ${ }^{16}$. 
at $40{ }^{\circ} \mathrm{C}$ with samples obtained from the same austenite single crystal, but with different orientations of the tensile axis ( 9 degrees of difference between each samples, in or$\operatorname{der} \underline{a}, \underline{b}, \underline{c})$. The curves show the maximum strain by superelasticity that can be obtained with these samples. At the maximum strain, the samples are fully martensitic and it has been verified by optical microscopy that only one variant is present, as shown in Fig. 8.

Stress induced transformation and recoverable strain due to superelasticity are affected by changes in crystallographic orientations of the tensile axis ${ }^{15,18,20}$. The sample $\underline{c}$ presents

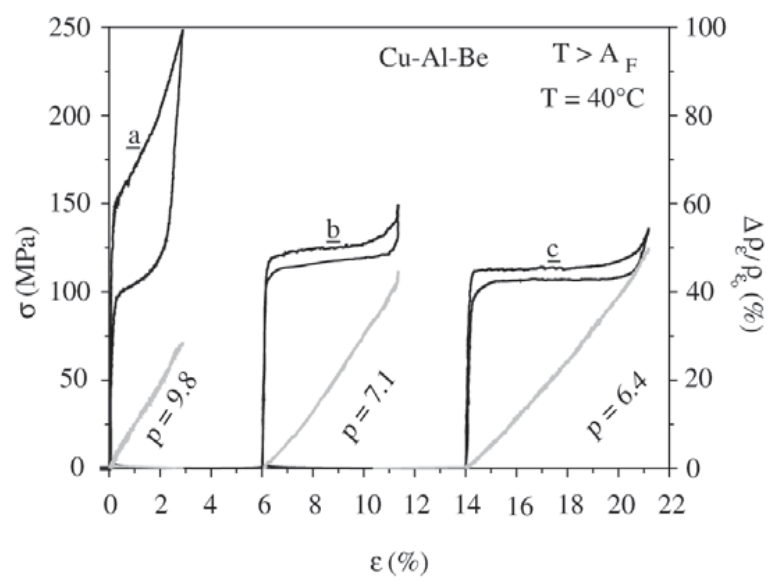

Figure 7. Superelastic tests for samples with different crystallographic orientations (CAB-2 sample). a maximum recoverable strain of about $7.0 \%$, indicating that the Schmidt factor of the induced variant is near 0.5 (tensile axis direction close to $<110>$ in $\beta$ phase coordinates). For the sample $\underline{a}$, the maximum strain is about $2.8 \%$ (tensile axis direction close to $<111>$ ). The Schmidt factor of the induced variant is then lowers than 0.5 . It is significant that the stress necessary to reach this low strain is higher than the one verified in sample $\underline{C}$. The stress $(\sigma) v s$. strain $(\varepsilon)$ curves demonstrates that three martensitic single variants with different crystallographic orientations was obtained.

Results of maximum strain and resistivity changes are indicated in Table 3 for the three samples. These results show that the difference between resistivity of austenite and martensite single variant is dependent on the crystallographic orientation of the variant. This observation can be made taking into account that the austenitic phase is isotropic, once that copper based SMA's have a body centred cubic structure. Thus, the different values of martensitic phase resistivity obtained for each sample reveal the influence of the direction of resistivity measurement. Theses results also clearly indicates that martensitic crystal presents a large resistivity anisotropy.

\section{Conclusion}

Coupled stress-strain with electrical resistivity measurements during martensitic transformation of $\mathrm{Cu}-\mathrm{Zn}-\mathrm{Al}$ and $\mathrm{Cu}-\mathrm{Al}-\mathrm{Be}$ single crystals alloys have been under taken in this study. A martensite single crystal has been obtained by two different ways: stressing of self-accommodated

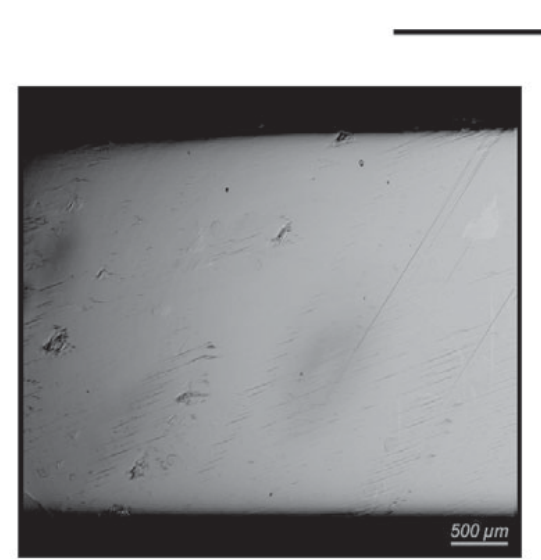

a) $\varepsilon=0.8 \%$

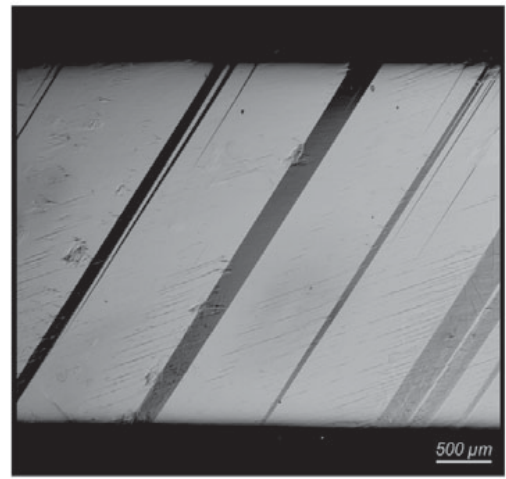

b) $\varepsilon=2.5 \%$

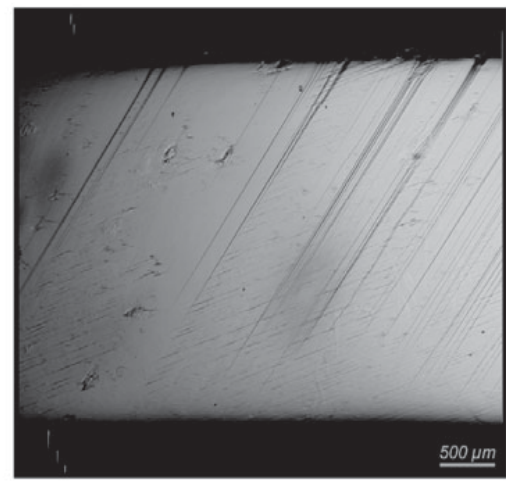

c) $\varepsilon=6.5 \%$

Unloading

Figure 8. Micrographs during formation of stress induced martensite (plates). For a strain level of $6.5 \%$, the sample is practically a single variant martensite crystal oriented by stress (CAB-2 alloy - sample $\underline{\mathrm{c}})$. 
Table 3. Resistivity changes for samples with different crystallographic orientations.

\begin{tabular}{|c|c|c|c|}
\hline Sample & A & B & $\mathrm{C}$ \\
\hline Maximum recovera & 2.9 & 5.3 & 7.2 \\
\hline $\begin{array}{l}\text { Resistivity changes be } \\
\text { and martensite }-\Delta \rho_{\varepsilon} / \rho\end{array}$ & 30 & 44 & 50 \\
\hline
\end{tabular}

martensite variants, which was produced by thermal transformation (variants reorientation process - operations $A+B=D$ ), and stressing directly from austenitic phase (stress induced martensite - operation $C$ ). The electrical resistivity changes of process $D$ is very close to the one obtained from superelasticity test. This resistivity is also much higher than the one of the randomly oriented polyvariant of martensite. This fact can be explained by the high electric resistivity anisotropy of the martensitic phase. To confirm this hypothesis, single variants of martensite were induced from single crystals of austenite with different crystallographic orientations. Electric resistivity measurements performed during the superelastic tests are a direct evidence of the dependence of resistivity with the direction of measurement in the martensitic phase (anisotropy).

\section{Acknowledgements}

Authors acknowledges the Coordenação de Aperfeiçoamento de Pessoal de Nível Superior (CAPES) and Conselho Nacional de Desenvolvimento Científico e Tecnológico (CNPq) for its financial support.

\section{References}

1. Stice, J.D.; Wayman, C.M. Metallurgical Transactions A, v. 13, p. 1687-1692, 1982.

2. Zhang, Y.; Hornbogen, E. Zeitschrift für Metalkunde, n. 78, v. 11, p. 777-783, 1987.

3. Van Humbeeck, J.; Janssen, J.; Mwamba, N.; Delaey, L. Scripta Metallurgica, v. 18, p. 893-898, 1984.

4. Mantel, M.; Rapacioli, R.; Guénin, G. Proceedings of the International Conference on the Martensitic Transformations, Japan, The Japan Institute of Metals, p. 880-885, 1986.

5. Ahlers, M. Proceedings of the International Conference on the Martensitic Transformations, Japan, The Japan Institute of Metals, p. 786-793, 1986.

6. Suzuki, T.; Kojima, R.; Fujii, Y.; Nagasawa, A. Acta Metallurgica, v. 37, p. 163-168, 1989.

7. Airoldi, G.; Ranucci, T.; Riva, G. Journal de Physique IV, v. 4, p. 439- 443, 1991.

8. Airoldi, G.; Ranucci, T.; Riva, G.; Sciacca, A. J. Phys.: Condens. Matter, v. 7, p. 3709-3720, 1995.

9. De Araújo, C.J.; Morin M.; Guénin, G. Materials Science and Engineering, v. A273, p. 305-309, 2000.

10. Gonzalez, C.H.; Quadros, N.F.; De Araújo, C.J.; Morin, M.; Guénin, G. Proceedings of the European Symposium on Martensitic Transformations and ShapeMemory - ESOMAT 2003, Cirencester, England, in press.

11. Airoldi, G.; Ranucci T.; Riva, G.; Sciacca, A. Journal of Phys.: Condens. Matter, v. 7, 3709-3720, 1995.

12. De Araújo, C.J.; Gonzalez, C.H.;, Morin, M.; Guénin, G. Materials Research, v. 4, n. 1, p. 181-188, 2001.

13. Airoldi, G.; Ranucci T. Materials Research Society, Mat. Res. Soc. Symp. Proc., v. 459, p. 323-328, 1997.

14. Pozzi, M.; Airoldi, G. Materials Science and Engineering, v. 273, 300-308, 1999.

15. Otsuka, K.; Shimizu, K. International Metals Reviews, v. 31, n. 3, p. 93-114, 1986.

16. Gonzalez, C.H. PhD Thesis: Institut National des Sciences Appliquées de Lyon, France, 184 p., 2002.

17. Bigeon M.J.; Morin M. Journal de Physique IV, v. 2 , p. 85-389, 1995.

18. De Vos, J.; Delaey, L.; Aernoudt, E. Zeitschrift für Metalkunde, v. 69, n. 8, p. 511-517, 1978.

19. Delaey, L.; Krishnan, R.V.; Tas, H.; Warlimont H. Journal of Materials Science, 1974, v. 9, p. 1521-1535, 1974.

20. Schroeder, T.A.; Wayman, C.M Acta Metallurgica, v. 27, p. $405-417,1979$. 
